\title{
Control of Systems of Reservoirs with the Use of Risk Analysis
}

\author{
P. Fošumpaur, L. Satrapa
}

A system of reservoirs is usually defined as a system of water management elements, that are mutually linked by inner and outer connections in a purpose-built complex. Combined elements consist of reservoirs, river sections, dams, weirs, hydropower plants, water treatment plants and other hydraulic structures. These elements also include the rainfall system, the run-off system, the ground water system, etc. A system of reservoirs serves many purposes, which result from the basic functions of water reservoirs: storage, flood control and environmental functions. Most reservoirs serve several purposes at the same time. They are so called multi-purposes reservoirs. Optimum design and control of a system of reservoirs depends strongly on identifying the particular purposes. In order to assess these purposes and to evaluate the appropriate set of criteria, risk analysis can be used. Design and control of water reservoir functions is consequently solved with the use of multi-objective optimisation. This paper deals with the use of the risk analysis to determine criteria for controlling the system. This approach is tested on a case study of the Pastviny dam in the Czech Republic.

Keywords: risk analysis, system of reservoirs, multi-objective optimisation, water supply, hydropower plant, fuzzy logic.

\section{Introduction}

In the field of controlling of reservoirs systems, it is often very difficult to formulate a reliable system of criteria. Control is usually defined as optimisation of structures and systems in terms of these appropriate criteria. This proper aims to assess the possibility of using risk analysis to define control criteria both in the phase of design and in the phase of operating hydraulic structures and systems of reservoirs.

Risk is defined in various ways in the literature. It is mostly explained as a combination of hazards, vulnerability and exposure. Vulnerability is obviously defined as the aptness of a structure or system to failure as a result of low resistibility. Exposure characterises the time period during which the structure or system is exposed to hazard. Hazards are characterised as the threat of an event, that tends to put the system into an undesirable state (mortality, economic losses, infrastructure failure, etc.). Hazards can be divided into natural hazards, caused generally by natural disasters (earthquakes, floods, tornados, fire, etc.), and hazards causes by human actions.

Risk can also be expressed by the theory of reliability. If the reliability is defined as the probability of the trouble-free state of the system, then the risk is given by the closeness of this probability to a certain event. Risk assessment is generally a very difficult problem. The following relation is often used:

$$
R=P \times C,
$$

where $R$ is the risk quantifier, $P$ is the probability of the occurrence of losses, and $C$ is monetary loss.

In water management, risk analysis is broadly developed in the field of dam construction. During the 20th International Congress on Large Dams in Beijing [1] significant attention was given to risk analysis. Most of the papers dealt with the analysis of dam failure. The safety of dams using risk analysis was studied by Nilkens et al [2]. The capacity of the risk analysis for EIA is described by Riha [3].

A system of reservoirs is usually defined as a system of water management elements that are mutually linked by inner and outer connections in a purpose-built complex. Combined elements are given by reservoirs, river sections, dams, weirs, hydropower plants, water treatment plants and other hydraulic structures. These elements also include the rainfall system, the run-off system, the ground water system, etc., etc.

Reservoirs and reservoir systems usually serve many purposes at the same time. According to their main purpose, reservoirs can be categorised as follows:

- water supply (drinking water, industry),

- flood control,

- irrigation,

- navigation,

- recreation,

- environmental function, etc.

\section{Methods}

Two basic phases need to be distinguished when dealing with reservoirs and reservoir system. The first phase, from the system point of view, is the design, while the second phase is the control and operation of existing systems and structures. Both phases involve the optimisation problem for the previously defined set of criteria. Optimisation of the dynamic system is then called control. Control is often defined as a systematic action on a control object that satisfies given aims. In the phase of reservoir design we generally talk about strategic control, and we are interested in optimising systems or structures from the long-term point of view. This phase aims at determining particular reservoir volumes in order to guarantee given reservoir purposes.

In the phase of real operation of previously designed reservoirs we usually try to optimise the system during all possible operating situations, namely during extremes such as floods, hydrological droughts, water quality control, etc. This kind of optimisation is called real time control, and we try to satisfy particular reservoir purposes taking into account given criteria, which can be formulated by minimising the measure of risk. In a period of hydrological drought, the risk of water supply failure rises, and it can be losses that can affect society. There are known approaches for assessing the risk from floods, hydropower production failure, etc. It is evident that 
risk analysis is a very powerful tool in the area of controlling reservoir systems.

When carrying out a risk assessment it is very important to make a loss estimation, which can be deterministic or stochastic. The deterministic approach involves loss estimation for only one previously measured event. By contrast to the stochastic approach includes the probability distribution of the studied events. This approach requires the simulation of numerous scenarios with the use of the Monte-Carlo method.

Determination of the risk with respect to the set of qualitative criteria is a very complicated problem in the area of the risk assessment. The criteria include the risk of exceeding the value of a minimum permissible maintained discharge downstream of the dam, the risk of deteriorating the environmental conditions in the downstream area, and the risk of a negative impact on the recreation function of a reservoir. In order to optimise a set of criteria which involves a certain number of qualitative requirements, we can use fuzzy set theory and the fuzzy logic theory put forward by Zadeh [4].

In our case study we deal with optimisation of the strategic control of a reservoir with respect to the following criteria:

- maintenance of the minimum discharge downstream of the dam,

- flood control,

- hydropower production,

- recreation.

To quantify the measure of risk of the first three criteria, the time-based reliability ( $R e$ ) of water supply according to duration is used [5]:

$$
R e=\frac{T-\Delta t}{T} \cdot 100[\%]
$$

where $T$ is the duration of the time series and $\Delta t$ is the sum of the duration of all failures that occurred in the series. The risk is then equal to a certain event (100\%). To quantify the recreation benefits of a reservoir, fuzzy set theory was used.

\section{Case study}

Multi-objective optimisation of strategic control with the use of risk analysis was tested on the Pastviny dam on the Divoka Orlice river (Czech Republic). This is a stone masonry arch dam built in 1939. The total storage capacity is $11 \times 10^{6} \mathrm{~m}^{3}$, including a flood control capacity of $2 \times 10^{6} \mathrm{~m}^{3}$. There are six spillways consisting of a fixed sill and located at three different elevations. The dam is equipped with two bottom outlets with an inner diameter of $1.4 \mathrm{~m}$. The Pastviny dam is a typical multipurpose dam. Its primary purpose is flood control, while the secondary purposes are: produc-

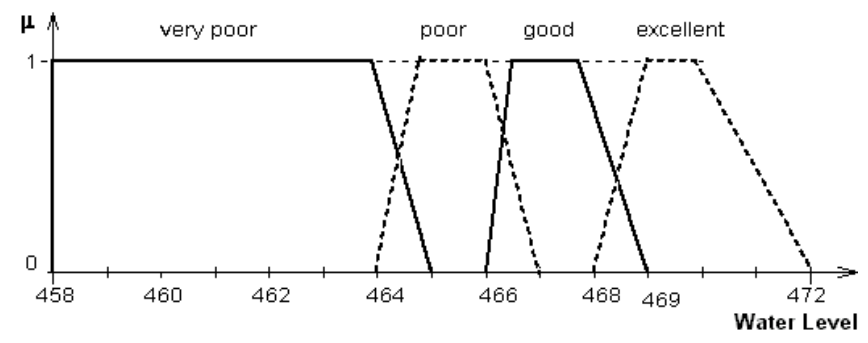

Fig. 1: Fuzzification of the recreation criterion

tion of hydroelectric power, discharge regulation in the downstream part of the Divoka Orlice river, and sport and recreation.

The criteria for minimum discharge maintenance, flood control and hydropower production were solved by using their reliability according to relation (2). The criterion for the recreation purpose was accomplished by using four fuzzy sets according to Fig.1. Each fuzzy set describes the quality of recreation by the membership degree index $\mu$ for the range of

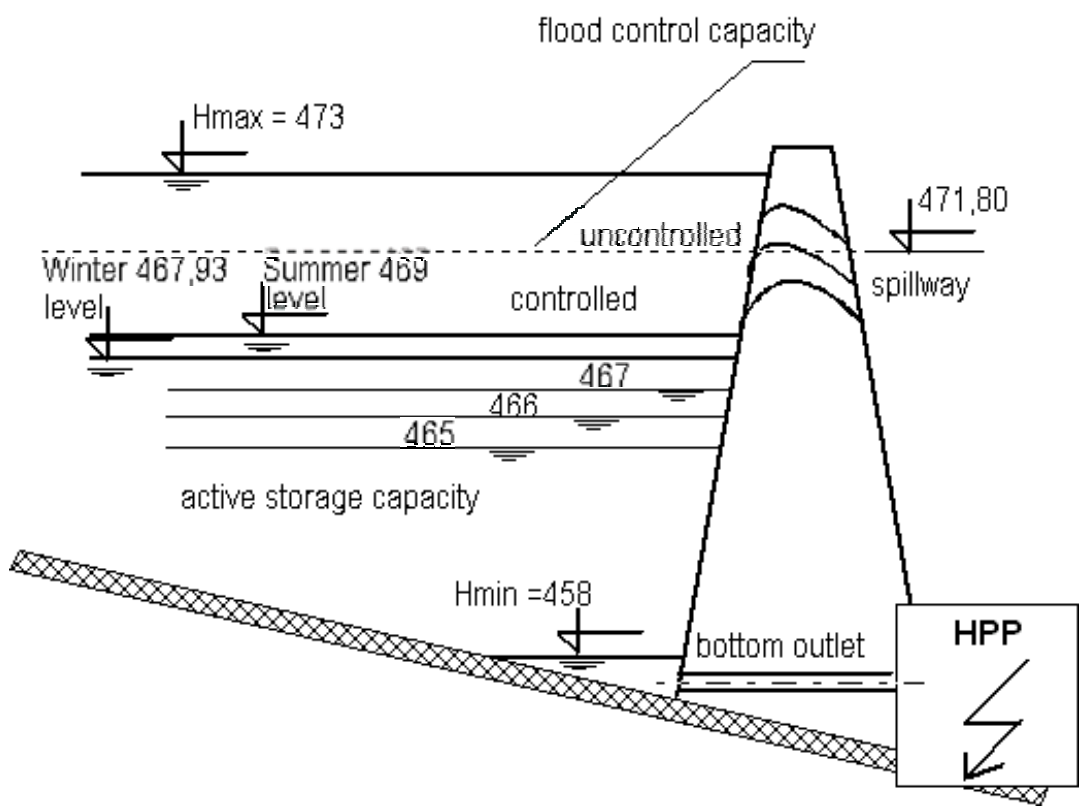

Fig. 2: Scenarios of the total reservoir volume allocation 
water levels in a reservoir. Fig. 1 shows that these are excellent conditions for recreation in the area around the full active storage capacity (altitude: $469 \mathrm{~m}$ ) and as the water level decreases the recreation conditions become worse.

Fig. 2 shows selected scenarios of the total reservoir volume allocation to the flood control capacity and the active storage capacity. The maximum water level in the reservoir is $473 \mathrm{~m}$, and different active storage capacitiesare defined for the summer and winter periods.

As not all the particular criteria are mutually scalable they should be normalised into the interval of $(0,1)$. Secondly, preferential weights should be chosen that agree with the order of significance of particular reservoir purposes. In actual operation, the order of significance order of particular reservoir purposes is established in the operating schedule of each dam. Our research also deals with the sensitivity analysis of the weight determination. Particular scenarios was performed with the use of the stochastic dynamic programming. Probability distribution of the input time series was adopted from the measured variables from the 1938-1995 period. Fig. 3 shows the dependence of the mean annual hydropower production $E$ on the choice of the active storage capacity level $M_{\mathrm{a}}$. The hydropower production values are related to the current level of mean annual production (100\%).

Fig.4 shows ratio of the flood control capacity $V_{r}$ and the flood volume with given return period $N$ with respect to the altitude of the water level of the active storage capacity $M_{\mathrm{a}}$.

The suitability of particular scenarios according to the recreation purpose of the reservoir was evaluated with the use of the membership degree of the actual water level to each fuzzy set during the simulation (Fig.1). The optimum scenario was then found by standard multi-objective optimisation methods.

\section{Conclusions}

We studied the use of risk analysis to quantify a suitable set of criteria for multi-objective optimisation of reservoirs and reservoir systems, which are usually intended to satisfy

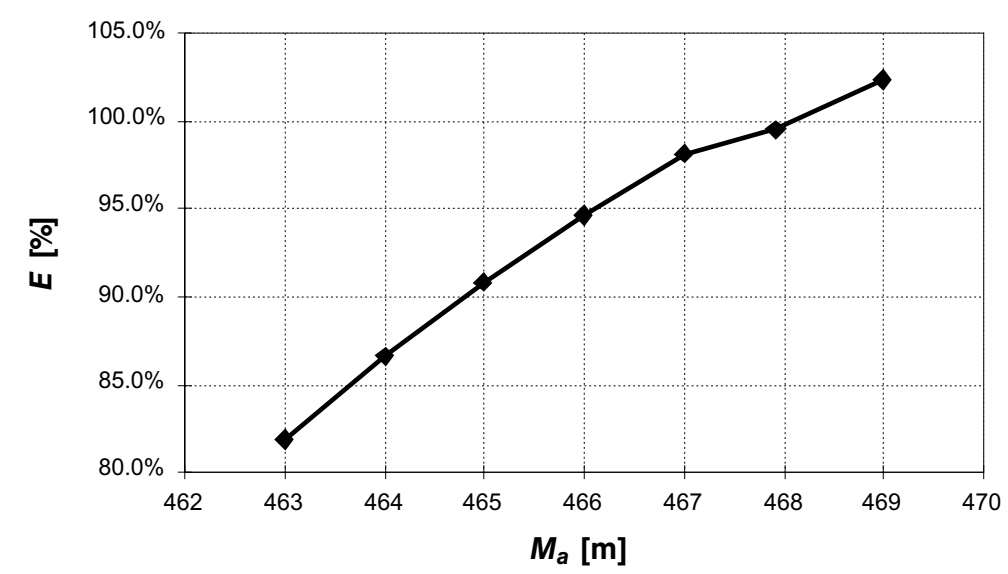

Fig. 3: Dependence of mean annual hydropower production on the choice of water level $M_{\mathrm{a}}$ of the active storage capacity

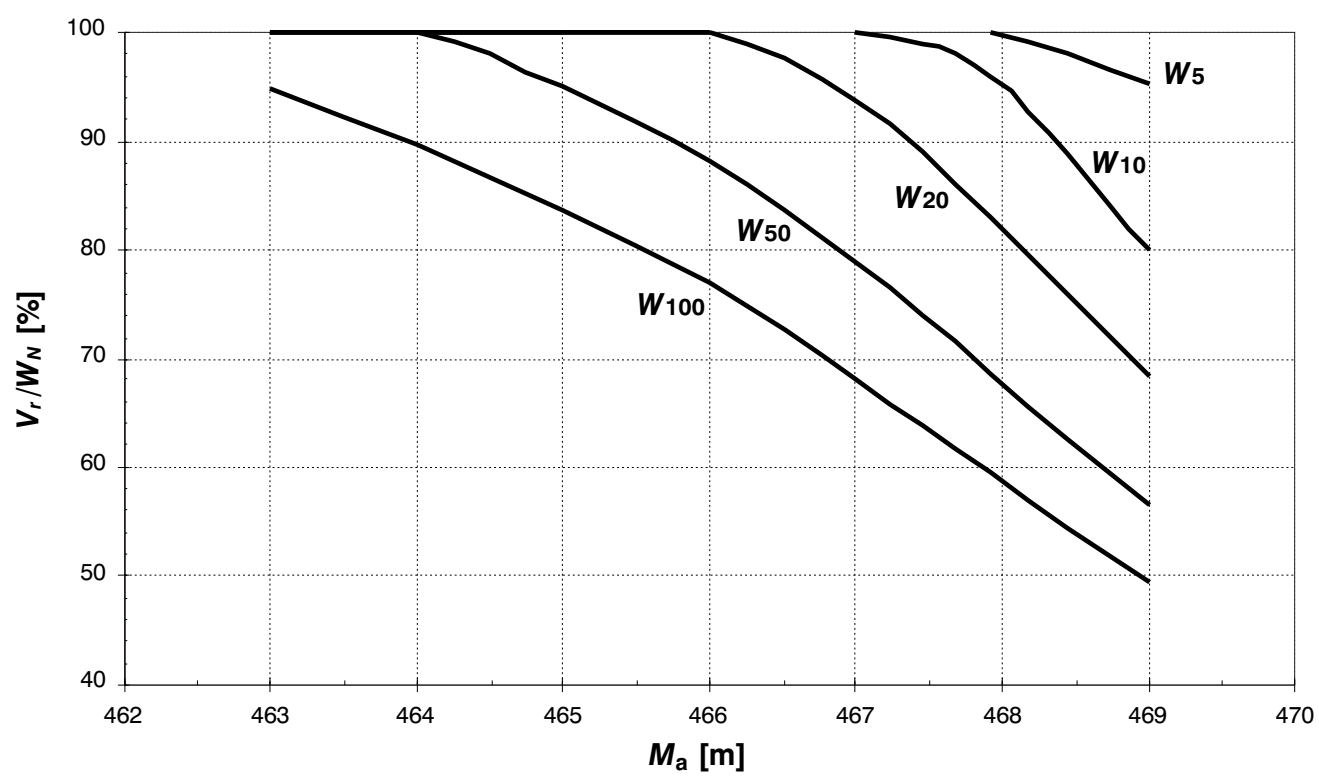

Fig. 4: Dependence of the ratio of the flood control capacity $V_{r}$ and the flood volume $W_{N}$ with a given return period $N$ with respect to the altitude of the water level of the active storage capacity $M_{\mathrm{a}}$ 
several purposes at the same time. These purposes can be in contradiction with each other. The described methodological approach of multi-objective optimisation was applied to a case study of the Pastviny dam in the Czech Republic, which serves for flood control, hydropower production, discharge regulation, and recreation purposes. Reliability theory was used for risk assessment of quantifiable criteria. The research has proved that fuzzy set theory is efficient for quantifying fully qualitative criteria, such as the recreation or environmental function of reservoirs.

\section{Acknowledgment}

This research has been supported by grant No. 103/02/0606 and grant No. 103/02/D049 of the Grant Agency of the Czech Republic.

\section{References}

[1] $20^{\text {th }}$ International Congress on Large Dams. Vol. 1, Question 76, Beijing China, Paris: ICOLD 2000, p. 896.

[2] Nilkens B., Rettemeier K.: "Risk Assessment Procedure for German Dams". In: Workshop on the occasion of the $69^{\text {th }}$ Annual Meeting of ICOLD in Dresden, 2001.
[3] Riha J.: Evaluation of Investment Impacts on Environment. Multipurpose Analysis EIA, Prague, Academia, 1995.

[4] Zadeh L. A.: Fuzzy sets. Information and control. Vol. 8, (1965), p.338-353.

[5] Votruba L., Broža V.: Water Management in Reservoirs. Elsevier: Prague SNTL, 1989.

Dr. Ing. Pavel Fošumpaur

phone: +420224354425

e-mail: fosump@fsv.cvut.cz

Ass. Prof. ing. Ladislav Satrapa, Ph.D.

phone: +420224354618

e-mail: satrapa@fsv.cvut.cz

Department of Hydrotechnics

Czech Technical University in Prague

Faculty of Civil Engineering

Thákurova 7

16629 Prague 6, Czech Republic 